\title{
Pedro González Gasca: UNA APROXIMACIÓN A SU OBRA Y PENSAMIENTO
}

Jesús Romero Salazar*

\section{Resumen}

El periodo de la historia mexicana conocido como Porfiriato (época de gobierno del general Porfirio Díaz, 1876-1910) ha sido objeto de estudio por más de un siglo. Este trabajo explora y analiza el pensamiento de Pedro González Gasca -político, geógrafo e historiador, originario del estado de Guanajuato, quien trazó las líneas entre los grandes ideales del orden científico-, considerándolo la guía elemental de su discurso historiográfico, es decir, de la manera de escribir e interpretar la historia durante las últimas décadas del siglo XIX, el cual fue escenario de ciencia positivista y legitimación de una era de "orden" y "progreso". El objetivo fue evidenciar un estudio moderno acerca de la historia y la geografía.

Palabras clave: Guanajuato, ciencia, historia, positivista, siglo XIX.

\begin{abstract}
The Mexican history period known as Porfiriato (time of general Porfirio Diaz's government, 1876-1910) has been a topic of study for more than a century. This work explores and analyses Pedro Gonzalez Gasca's thought -politician, geographer and historian, born in 1853 in Guanajuato, who traced outlines between "enlightened" ideals of orderliness scientific-, considering it the guiding element of his historiography discourse during the final decades of the nineteenth century, that is to say, in a context of positivist science and legitimation of an "order" and "progress" era. The objective was to make evident a modern study about the history and geography.
\end{abstract}

Keywords: Guanajuato, science, history, positivist, nineteenth century.

* Universidad de Guanajuato 
Sin duda la segunda mitad del siglo XIx en México fue el escenario donde se conjugó un gran número de visiones, conformando una riqueza historiográfica en diversos temas, como el estudio de climas, razas, costumbres, el medio geográfico, la biología, la medicina y, por supuesto, la historia, entre muchos otros. De igual manera, la cantidad de personajes que formaron parte del ambiente intelectual es enorme; se tuvo la participación de nacionales y extranjeros, así como la institucionalización de las ciencias. En dicho periodo se buscó legitimar cierto "modo de pensar" civilizatorio, regido por un carácter científico, desde el cual se pudiera justificar la manera en que el gobierno de entonces, encabezado por Porfirio Díaz, ejercía la política.

En este ambiente intelectual participó Pedro González Gasca, quien nació el 28 de junio de 1853, en la entonces villa de Salamanca, Guanajuato. Comenzó sus estudios de farmacia en el Colegio del Estado, pero los abandonó en 1867 para iniciar su trayectoria política, primero como secretario, luego como visitador de jefaturas políticas, inspector de censo y jefe político. Incursionó, además, en ámbitos como la historia, la geografía, la política y la etnología. Se desempeñó como procurador y jefe político en los municipios de Dolores Hidalgo, San Miguel Allende, Purísima del Rincón, Valle de Santiago, Apaseo, Moroleón y, por supuesto, su natal Salamanca.

En 1895 el gobierno del estado lo nombró delegado para el XI Congreso de Americanistas, celebrado el mismo año en la ciudad de México; posteriormente, perteneció a la Sociedad Mexicana de Geografía y Estadística, a la Sociedad Antonio Alzate y a la Alianza Científica Universal; en 1910 fue nombrado ayudante de bibliotecario del Museo Nacional de Arqueología, Historia y Etnología por la Secretaría de Instrucción Pública y Bellas Artes; en 1912 esta institución le asignó la cátedra de etnología, supliendo al maestro Andrés Molina Enríquez. Falleció en octubre de ese mismo año.

Por otra parte, el quehacer historiográfico del salmantino Pedro González incluyó pequeños artículos, apuntes y ensayos históricos de mayor profundidad teórica y metodológica, entre los que destacan la Geografía local del Estado de Guanajuato (1904) y los Apuntes históricos de la ciudad de Dolores Hidalgo (1892); escribió también obras como Hombres notables de Salamanca y del 
Estado de Guanajuato (1895), Calendario Azteca o La Piedra del Sol (1896), Algunos puntos y objetos monumentales antiguos del Estado de Guanajuato (1895), ¿Cuándo termina el siglo XIX? (1899), Atlas de Guanajuato (1905), Geografía elemental de Guanajuato (1905) y Desarrollo de las ideas cientificas en México (1911); además se le atribuye la autoría de los Apuntes históricos de la Ciudad de Salamanca (1909).

A partir de esta breve semblanza podemos destacar algunas noticias que sirven para enmarcar su pensamiento y obra, de cara a una orientación positivista ${ }^{1}$ sobre la historia y las expectativas de su tiempo. En la mayoría de sus textos es notoria su inclinación a ponderar la parte cronológica de los sucesos -ejemplo de ello es su obra Desarrollo de las ideas científicas en México en una centuria de vida independiente, inmersa en un contexto donde el desarrollo económico se convertiría en el proyecto político y social de aquel momento.

Además, su obra histórico-geográfica permite advertir aspectos como el clima, la flora, la fauna, los vestigios, la historia política y educativa, los rasgos culturales, entre otros, en un contexto político y cultural donde las asociaciones científicas se presentaban como espacios para propiciar el intercambio de investigaciones de diversa índole, con miras a "profesionalizar" a los intelectuales en determinadas disciplinas.

En ese sentido, la constante participación de Pedro González en la Sociedad Mexicana de Geografía y Estadística fue, en su momento, un factor clave para dar a conocer sus diversos estudios, ya que en correspondencia con el ideal de la época, tal dependencia -añadiendo, además la Sociedad Mexicana de Historia Natural, el Instituto Médico Nacional y la Sociedad Científica Antonio Alzate, entre otras instituciones-, sirvió de catalizador para promover las inquietudes científicas y difundir las tendencias del pensamiento.

Este espíritu cientificista configura una manera particular de interpretar y legitimar dicha teoría desde un determinado escenario intelectual, político y social, motivado por el interés de construir y dar a conocer una identidad con base en lo que estudia, reconociendo en los vestigios y el propio pasado la imagen para proyectar y representar un sentido de pertenencia a cierta

1 Postura filosófica planteada por el filósofo francés Augusto Comte, quien propone una doctrina sobre el origen del conocimiento, del mundo, la historia y el hombre mismo, desde diferentes estadios: el teológico, representado por la Antigüedad; el metafísico, por la Edad Media, y el positivo, identificado con el siglo xIX. 
región (Guanajuato) y, posteriormente, a una nación; con ello reafirma que "la geografía local se aprende con los pies".

Ahora bien, para adentrarse en la obra de González es conveniente revisar las ideas que prevalecieron durante la segunda mitad del siglo XIX en México. ${ }^{3}$ Como referente inmediato se suele pensar en el positivismo, dada su hegemonía y determinante influencia en los ámbitos educativo y político; sin embargo, este escenario del pensamiento nos demanda una postura abierta a otras manifestaciones, que también tuvieron incidencia en dicho momento en Europa, con miras a identificar sus posibles influencias en el marco de ideas del México del siglo XIX.

Vale la pena aclarar que esta corriente representa (entre otras, como el darwinismo, el evolucionismo, etc.) una visión de mundo que otorgó al "método" toda la validez para sustentar el conocimiento, es decir, dicha postura se enfocó en ir acumulando "dato por dato" para llegar a una explicación general de un fenómeno. La prioridad del positivismo consistió en abordar aquello que se podía evidenciar y comprobar, para dejar de lado lo que simplemente pertenecía al ámbito metafísico.

También es necesario tener presente una serie de circunstancias, como el hecho de que Pedro Contreras Elizalde, ${ }^{4}$ amigo de Gabino Barreda, fue quien propició el acercamiento con el francés Augusto Comte, el "padre" de dicha doctrina; y que, posteriormente, Barreda se encargó de difundir tales ideales en México. En 1867, gracias a algunos nexos familiares con el presidente Juárez, Barreda le propondría cierta reforma que, según él, debía gestarse desde la educación. Fiel representante del lado liberal, sus ideales quedarían plasmados en su Oración Cívica, documento pronunciado el 16 de

2 González, Geografía local del Estado de Guanajuato, p. 2.

3 "El siglo XIX en México está lleno de luchas y gravísimos problemas en lo interno y en lo externo y no propició la consolidación de un esfuerzo científico estructurado y uniforme [...] la dictadura apoyada en el 'Partido Científico' formado por positivistas, tampoco consintió mayores libertades a los disidentes científicos. No obstante, existían la Sociedad de Geografía y Estadística que publicaba el Boletín, la 'Científica Antonio Alzate' que publicaba sus Memorias, y otras muchas, más efímeras. En los diversos estados de la república había instituciones (como el Colegio del Estado de Guanajuato o la Sociedad de Ingenieros de Jalisco) donde las inquietudes científicas tuvieron oportunidad de manifestarse más o menos organizadamente o aun con cierta timidez". Moreno, La polémica del darwinismo, p. 18.

4 Pedro Contreras Elizalde es considerado el primer positivista mexicano. Nació en 1823 o 1824. Estudió medicina en Francia, donde tuvo cercanía con los doctores Robin y Segond, ambos discípulos de Comte. Posteriormente, llegó a ser miembro de la Sociedad Positivista. 
septiembre de 1867 en la ciudad de Guanajuato y que permite ver, al buscar sustituir a la Iglesia católica por una religión que se apoyara en un método, con evidencia y rigor en su investigar, una marcada posición anticlerical y cierta identificación con el pensamiento de Comte.

Por lo tanto, resulta notable la influencia del pensamiento europeo en el contexto mexicano de la época. Para destacar dicho aspecto, William Raat afirma que los hombres de finales del siglo XIX mantienen una actitud cientificista, esto es, una pretensión al saber científico, más que una actitud propiamente positivista; según Josefina Mac Gregor "El positivismo, pues, no se cierra a las nuevas ideas, sino que las toma en cuenta de acuerdo con su utilidad social". ${ }^{5}$

Vale la pena destacar que esta tendencia se propagó en España, Italia y América Latina, particularmente en Brasil y México. En este último tuvo su semillero en la Escuela Nacional Preparatoria, debido a la influencia directa de dos discípulos de Comte: Gabino Barreda ${ }^{6}$ y Porfirio Parra. ${ }^{7}$ Otros seguidores de la corriente comteana en México fueron Francisco Bulnes, Ricardo García Granados y Andrés Molina Enríquez.

Antes de que Gabino Barreda estableciera la Escuela Nacional Preparatoria en 1867, en México prevalecía, en cuanto a la historiografía, el empirismo propio de eruditos como Orozco y Berra, Ramírez y García Icazbalceta. Por otro lado, el liberalismo anteponía el factor ideológico a lo que se investigaba y se escribía; y el romanticismo, sin dejar a un lado las ideologías, tendía a las grandes recreaciones históricas. En otras palabras, si bien el positivismo encontró ciertas condiciones que le permitieron ser aceptado por los intelectuales del momento, coexistía con otras doctrinas o teorías; sin embargo, el discurso comteano sirvió, en muchas ocasiones,

5 Mac Gregor, reseña del libro El positivismo durante el Porfiriato, 1876-1910, p. 224.

6 "Gabino Barreda fue el hombre encargado de preparar a la entonces joven burguesía mexicana para dirigir los destinos de la nación mexicana. El instrumento ideológico del que se sirvió el maestro mexicano fue el positivismo". Sierra, Evolución política, p. 423.

7 Porfirio Parra (1854-1912) estudió medicina y ejerció tal disciplina en el Hospital Juárez; fue catedrático de anatomía descriptiva y de patología externa en la Escuela de Medicina. Desde sus años de preparatoria fue alumno de Gabino Barreda, y perteneció a diferentes asociaciones científicas, artísticas y literarias, entre ellas la Academia Nacional de Medicina, la Sociedad de Geografía y Estadística y la Academia Mexicana de la Lengua. Fundó los periódicos El Método y El Positivismo. Se le considera como maestro de la segunda generación de positivistas. Véase: Ortega y Medina, Polémicas y ensayos, p. 356. 
para justificar y legitimar algún discurso o bien una actividad que no fuera considerada "científica" en dicho momento.

En consecuencia, en el escenario mexicano, desde la perspectiva de Álvaro Matute, "existe mucha confusión acerca de lo que se debe entender por historiografía positivista mexicana. Es posible leer o escuchar que la palabra 'positivista' se aplica a autores y obras mexicanos que no lo son en rigor". 8

Y es por ello que, a finales del siglo XIX, el historiador reflexiona sobre su propio quehacer, asume desde el interior de su disciplina que no debe limitar su estudio a una mera descripción, sino reflexionar sobre el sentido y el modo de escribir la historia. Ante esto, Pedro González advierte que el historiador ${ }^{9}$ debe identificar las coordenadas espacio-tiempo al momento de analizar cualquier hecho; además señala que:

[...] la historia no se debe limitar a una serie de curiosidades donde los últimos sucesos no deben ser los preferidos, sino caracterizarlos en su tiempo y en su carácter cronológico [...] La historia sin la cronología es como un palacio de gran ámbito, pero que se halla sin ventanas por donde entre la luz: todo será confusión, todo tropiezos. ${ }^{10}$

Lo anterior nos habla de un paradigma que se compartía en ciertos círculos de intelectuales de la época; ${ }^{11}$ para ellos los múltiples coloquios y congresos científicos, donde participó el propio Pedro González, sirvieron igualmente de escenario a otros escritores, médicos, abogados, etc., para tener una visión general de la historia y el rigor o carácter científico al escribirla.

El positivismo en la historiografía asumió, por tanto, que la verdad científica tenía un sustento basado en lo empírico, en la observación de los hechos, en

8 Matute, Pensamiento historiográfico, p. 103.

9 "El propósito de un historiador depende de su punto de vista $[\ldots]$ nuestra pretensión es más modesta: tratamos, simplemente, de exponer cómo ocurrieron, en realidad, las cosas. El propósito y la materia determinan la forma". Ranke, Pueblos y Estados en la historia moderna, pp. 37-38.

10 González Gasca, ¿Cuándo comienża el siglo XX? pp. 1-2.

11 Paradigma es un concepto manejado por el filósofo de la ciencia Thomas S. Kuhn, quien lo concibe como una serie de valores, preguntas, referentes, compartidos por una comunidad de científicos. 
este caso a través del documento, el cual constataba lo sucedido [...] el discurso del historiador debía ser imparcial y veraz, convirtiéndose este último en un juez que veía, examinaba, y fallaba. ${ }^{12}$

Este carácter científico representó, para dicho autor, el principio desde el cual se elabora la crítica de la historia al momento en que un historiador pone en tela de juicio los hechos; además, considera necesario realizar ciertas preguntas y lecturas no sólo de los documentos, sino detenerse en los propios monumentos, la geografía en general y las propias rocas como "testigos de ese pasado".

Al menos ciertos científicos o intelectuales de finales del siglo XIX asumieron que era el "momento" de lograr el cambio tan esperado por una sociedad. Fue una época en que el pensamiento moderno se propuso mostrar los productos culturales y científicos de su siglo como superiores a los realizados en el pasado.

Por otra parte, si bien no encontramos en los textos de Pedro González una afirmación en la que se asuma como fiel seguidor de cierta doctrina o corriente de pensamiento (positivismo o darwinismo, por citar sólo dos corrientes de pensamiento), tampoco se encontraba ajeno a la discusión entre los intelectuales o miembros de las diferentes asociaciones científicas, quienes sin duda tenían a la mano aquellas obras de vanguardia para dicho momento.

De tal manera que, a lo largo de los escritos de González, la ciencia representa el eje fundamental para el estudio histórico; es la "medida" de todo conocimiento, es la condicionante de la historia, constituye los anteojos críticos al momento de deducir e interpretar el pasado y sus objetos. En sus textos y discursos, el salmantino se encarga de fusionar y verificar la intuición con el dato duro, la cifra con la representación al momento de hablar sobre la época antigua. Por la misma razón, se centra en los rasgos que van de un momento o época a otra, la formación del ambiente, su composición, flora y fauna, todo en una visión cientificista sobre el gran proceso civilizatorio.

Resulta característico que a fines del siglo XIX, cuando el gobierno porfirista buscó "dar otra cara" del país con base en su modelo económico-político, se

12 Moya, La nación como organismo, p. 20. 
estuviera planteando la necesidad de llegar a concretar el ansiado "orden". En ese momento, el mexicano advirtió su condición frente a los "otros", de ahí el interés por reducir la distancia en cuanto al progreso logrado por otras naciones; por ello, se toma la iniciativa de comunicar el vasto territorio a través de las primeras redes ferroviarias, caminos, correos, telégrafos, fábricas, industrias, talleres, escuelas.

Esta visión explica el interés por tener cifras, estadísticas y aprovechar los datos de las diferentes disciplinas como la geografía, la antropología o la historia misma, mientras se buscaba proyectar la imagen de una nación trasformada y moderna, lo cual obligó a la historia a volcar la mirada hacia sí misma y cuestionar su propio quehacer, su manera de explicar y abordar el pasado, al institucionalizarse tomando un lugar en la academia.

A principios del siglo xx la teoría de la historia llevó a cabo una reflexión sobre el devenir del conocimiento histórico. Mientras se ratificaba el fundamento histórico, la historiografía política experimentó un lento cambio como disciplina en busca de cumplir ciertos alcances, diferentes de los pretendidos por una historia universal o Magistra Vitae, en la revaloración de los elementos teóricos donde el historiador asume un contexto, vincula diversas herramientas y asume un proceder sui generis en la forma de estructurar su explicación.

Por otra parte, en la antesala del siglo xx se puede advertir cómo la historia se convierte en "historias", al situarse frente a otros lenguajes, interpretaciones, valores, métodos, etc., y abordar la realidad desde un enfoque más complejo, donde la filosofía y la historia conviven. Tanto los filósofos de la historia como los historiadores se preguntaron por el estatus científico de la historia, y ambos asumieron que estaba en transformación.

Como ya se mencionó, el hecho de que la historiografía se encontrara más vinculada e identificada, en cuanto a preceptos, con el positivismo -cuya concepción del proceso histórico es que se dirige siempre a un estado superior, hacia lo perfecto, como herencia de la Ilustración-, no excluyó que otras corrientes de pensamiento influyeran en los modos de escribir la historia. Queda claro, entonces, que el positivismo no se reduce a la figura de Augusto Comte, y que es conveniente tomar en cuenta a pensadores como Enrique Thomas Buckley, Herbert Spencer e Hipólito Taine. 
Tras esta serie de cambios en el estudio y dominio de la naturaleza y las formas de producción, el avance de la técnica parecía la solución a la problemática social. Ante la necesidad de dotar a la historia del carácter de ciencia, el positivismo se presentó como "la respuesta", con la condición de que la historia fundamentara su quehacer en la recopilación de datos duros, pensando en que ello podría ser útil a la "madre de todas las ciencias": la sociología. A partir del presente trabajo se pueden advertir los múltiples estudios que se desprenden del quehacer historiográfico local, en torno a la vida y obra de González, en cuanto al papel de la ciencia, la historiografía, la geografía y de su interés como historiador.

No sólo un edificio sino una moneda, una estatua, un cuadro, una vasija, un mueble, un manuscrito, una inscripción, etc., de la antigüedad, pueden y deben ser mirados como monumentos que caen bajo su dominio [de la historia], y la importancia de esos conocimientos es evidente, cuando se ve cómo los pueblos tienden á perpetuar sus hechos notables, sus ideas y sentimientos que informan su vida, los testigos de su religión y de su historia, sus lenguas, y en general sus costumbres y tradiciones, ó las leyendas de sus santos. ${ }^{13}$

Es pertinente destacar que Pedro González Gasca desarrolló su obra histórico-geográfica cuando el quehacer y la escritura de la historia eran motivo de un constante debate entre abogados, médicos, geógrafos y educadores. Consideraba el estudio de la geografía un tanto difícil para los alumnos. Tal dificultad la atribuía a la forma en que era enseñada: de manera abstracta, sin método racional, como una lista árida de nombres, desprovista de ese encanto que para los niños tiene lo desconocido cuando se sabe despertar en ellos la atención. Por ello, recomendaba dejar de lado la enseñanza seca y abstracta, y en su lugar realizar descripciones animadas y embellecidas por imágenes brillantes y pinturas vivas, como se puede constatar en la Geografía elemental.

González pretendió construir una obra histórica a partir de formar un bagaje intelectual, evidenciando en su apuntes y notas los "caminos recorridos", como se puede constatar cuando se refiere al estudio de

13 González, Boletin de la Sociedad Mexicana de Geografía y Estadística (en adelante BSMGE), p. 315. 
la geografía; sin embargo, pensaba que toda esa experiencia debía ser plasmada en la escritura, con desarrollo y madurez, hasta cobrar cierta vigencia, carácter y vida propia en ensayos que evidenciaran la fuerza de la palabra escrita, reflejaran denuncias, juicios e interpretaciones sobre hechos y actores, y aportaran un conocimiento de la historia nacional.

Sus textos plasman el espíritu de una época. El papel central que le otorga a la ciencia, a la geografía o "ciencia de los lugares", como él la llamaba, el estudio de fósiles, de las capas terrestres, son relevantes para entender un marco histórico mayor, aspecto que siempre invita a dar una nueva lectura a sus textos y a reflexionar sobre su contenido, haciendo de la historiografía una actividad y expresión de los hombres y sus relaciones con su espacio, al cual González define a partir de que: "El individuo personal o colectivo se adapta al medio ó perece, saca del medio los elementos de subsistencia y á poco viene á ser producto de medio tan íntimo, que se convierte metafóricamente hablando en el mismo medio transformado". ${ }^{14}$

De esta manera, siempre refleja un interés por elaborar un discurso que logre combinar el rigor de un método, el apego al orden del estudio, con la propia búsqueda del conocimiento y, a su vez, con un apasionante interés por plasmar la historia etapa por etapa; González concilia racionalismo, intuición, imaginación y un poco de nostalgia al presenciar la agonía del siglo XIX, pues confiaba en que con el adelanto científico se lograría resolver cualquier obstáculo que impidiera llegar al bienestar social.

Al mismo tiempo, en cada uno de sus escritos pone en evidencia una fuerte identidad con el estado de Guanajuato, al cual dedica gran parte de su obra con el propósito de resaltar su riqueza y rasgos por estudiar.

La antigua fisonomía del suelo de Guanajuato y de sus habitantes, vistos de improviso, nos conduciría á la opinión no definida que nos formamos de un monolito lleno de figuras, en que admiramos lo bizarro del dibujo y su exquisita ejecución, por los estudios de la combinación de las líneas rectas con las curvas: sólo palparíamos el trabajo que los artífices tuvieron y no las comprenderíamos ni nos podríamos figurar los medios que tuvieron para realizarlas, si ignoramos la

14 González Gasca y Ramírez, Geografía elemental del Estado de Guanajuato..., pp. 5-6. 
instrucción que pudieron alcanzar, y no apreciamos su cultura comparándola con la nuestra. ${ }^{15}$

Por último, se puede puntualizar que Pedro González llevó a cabo su obra y pensamiento en un momento cuyo marco o escenario político y cultural estuvo marcado por el auge científico, en el que las asociaciones científicas y los grupos de intelectuales desarrollaron un interés mutuo por intercambiar sus estudios e investigaciones, siempre reflejando una intención por explicar su pasado, asumiendo que el estudio de la ciencia y la geografía son vitales para entender la historia y su cronología, en un constante diálogo consigo mismo, su obra y su propia época.

\section{Bibliografía}

González Gasca, Pedro e Ignacio Ramírez, Geografía elemental del Estado de Guanajuato. Lecciones formadas para cubrir la asignatura de tercer año de primaria, México, Imprenta de Braulio Acosta, 1905, (Biblioteca digital Emeterio Valverde de la UANL).

González Gasca, Pedro, ¿Cuándo comienza el siglo XX?, Valle de Santiago, (sin dato de imprenta), 1899.

, El desarrollo de las ideas científicas y su infuencia social y politica durante

una centuria de vida independiente, México, Tipografía de la viuda de F. Díaz de León, 1911.

Geografía local del Estado de Guanajuato, Tip. de la Esc. Industrial Militar J. O. G., 1904.

, Apuntes históricos de la ciudad de Dolores Hidalgo, Celaya, Impr. Económica, 1892.

, "Discurso de recepción", en Boletín de la Sociedad Mexicana de Geografía y Estadística, Imprenta García Cubas y Hermanos, 5 a época, núm. 7, tomo IV, 1905.

2000 .

Geografía local del Estado de Guanajuato, México, Editorial La Rana,

15 González Gasca, BSMGE, p. 315. 
, "Discurso de recepción", en Boletín de la Sociedad Mexicana de Geografía y Estadística, Imprenta García Cubas y Hermanos, 5a época, núm. 7, tomo IV, 1905.

Matute Aguirre, Álvaro, Pensamiento historiográfico mexicano del siglo XIX. La desintegración del positivismo (1911-1935), México, Fondo de Cultura Económica/unam, 1999.

Mac Gregor Gárate, Josefina, reseña de El positivismo durante el Porfiriato, 1876-1910, México, SEP, 1975, en Álvaro Matute (ed.), Estudios de bistoria moderna y contemporánea de México, México, Universidad Nacional Autónoma de México, vol. 6, 1977.

Mendoza Vargas, Héctor, Lecturas geográficas mexicanas. Siglo XIX, México, UNAM, 1999.

Molina Enríquez, Andrés, Los grandes problemas nacionales, México, ERA, 1978.

Moreno, Roberto, La polémica del darwinismo en México: Siglo XIX, México, UNAM, 1984.

Moya López, Laura Angélica, La nación como organismo. México su evolución social 1900-1902, México, UAM, 2003.

Ortega y Medina, Juan (sel., introd. y notas), Polémicas y ensayos mexicanos en torno a la historia de México, México, UnAm, 2001.

Ranke, Leopold von, Pueblos y Estados en la historia moderna, México, Fondo de Cultura Económica, 1948.

Sierra, Justo, Evolución política del pueblo mexicano, México, Casa España, 1940. 